\title{
Analisis Technology Acceptance Model (TAM) Terhadap Penggunaan Aplikasi Gojek Pada Mahasiswa di Kota Palembang
}

\author{
Nyayu Sakinatul Mardhiyah ${ }^{1 *}$, M. Rusydi ${ }^{2}$, Peny Cahaya Azwari ${ }^{3}$ \\ 1, 2, 3Universitas Islam Negeri Raden Fatah Palembang \\ 1nyayusakinah6@gmail.com, ${ }^{2}$ mrusydi_uin@radenfatah.ac.id, ${ }^{3}$ penycahayaazwari_uin@radenfatah.ac.id \\ *Penulis Korespondensi
}

\begin{abstract}
The purpose of this research is to find out how technology in the form of gojek can be well received by colleges in Palembang. The framework has been developed based on the TAM and TRA with quantitative research methods in the form of SEM Amos 21. The results of the research are usefulness and ease of use have a positive and significant effect on behavioral intention of use, usefulness, ease of use and behavioral intention of use have a positive and significant effect on actual system use, the last usefulness and ease of use have a positive and significant effect on actual system use through behavioral intention of use. Based on these results it can be concluded that the subject has been well received by Palembang colleges through TAM and TRA as the grand theory.
\end{abstract}

Keywords: Gojek, TAM, SEM Amos

\begin{abstract}
Abstrak
Penelitian ini bertujuan untuk mengetahui bagaimana teknologi gojek dapat diterima dengan baik pada kalangan mahasiswa di kota Palembang. Kerangka pemikiran telah dikembangkan berdasarkan TAM dan TRA dengan metode penelitian kuantitatif berupa perangkat SEM Amos 21. Hasil penelitian menyatakan bahwa usefulness dan ease of use berpengaruh secara positif dan signifikan terhadap behavioural intention of use, usefulness, ease of use dan behavioural intention of use berpengaruh secara positif dan signifikan terhadap actual system use, yang terakhir usefulness dan ease of use berpengaruh secara positif dan signifikan terhadap actual system use melalui behavioural intention of use. Berdasarkan hasil tersebut dapat disimpulkan bahwa gojek telah diterima dengan baik di kalangan mahasiswa kota Palembang melalui TAM dan TRA sebagai grand theorynya.
\end{abstract}

Kata kunci: Gojek, TAM, SEM Amos

\section{Cara Mengutip:}

Mardhiyah, N. S., Rusydi, M., Azwari, P. C. (2020). Analisis Technology Acceptance Model (TAM) Terhadap Penggunaan Aplikasi Gojek Pada Mahasiswa di Kota Palembang. Esensi: Jurnal Bisnis dan Manajemen. Vol. 10 (2): 169-180. DOI: https://doi.org/10.15408/ess.v10i2.16455 


\section{PENDAHULUAN}

Gojek memiliki lebih dari 1 juta driver yang tersebar di seluruh Indonesia. Hal ini berimplikasi terhadap jumlah pengguna gojek. Pada aplikasi playstore terlihat jumlah pendownload aplikasi gojek sudah lebih dari 50 juta (Tentang Kami / Gojek, n.d.). Berdasarkan Aplikasi AP terlihat bahwa terjadi peningkatan gojek secara masif dibandingkan grab (App $\mathrm{AP}$, diakses 2020, n.d.). Untuk melihat lebih jauh fenomena tersebut, maka penelitian ini akan menggunakan teori Technology Acceptance Model (TAM) (Kock, 2017).

TAM adalah disertasi dari Fred Davis yang diterbitkan pada tahun 1989. teori ini digunakan untuk memprediksi dan menjelaskan bagaimana penggunaan teknologi menerima dan menggunakan teknologi tersebut dalam kehidupan sehari-hari (Agustini, 2014).

Dua unsur yang berperan penting dalam integrasi teknologi sehingga masyarakat bersedia menerima teknologi tersebut yaitu persepsi manfaat (usefulness) dan persepsi kemudahan dalam penggunaan (ease of use) melalui minat guna (behavioural intention of use). Menurut Adam, Nelson dan Told usefulness adalah tingkat kepercayaan seseorang terhadap penggunaan suatu subjek yang dapat memberikan manfaat bagi penggunanya. Menurut Davis ease of use adalah suatu keadaan di mana seseorang yakin bahwa dengan menggunakan sistem atau teknologi tersebut tidak diperlukan usaha apapun (free of effort). Usefulness dan ease of use akan menimbulkan Behavioural intention of use. Behavioural intention of use adalah adalah tingkatan seseorang mengenai rencana secara sadar untuk melakukan atau tidak melakukan suatu perilaku di waktu yang akan datang yang telah ditentukan sebelumnya (Permana, 2017). Niat perilaku penggunaan adalah hal yang wajib ada dalam diri manusia berdasarkan potongan hadits arba'in nawawi yang pertama. Rosulullah SAW bersabda:

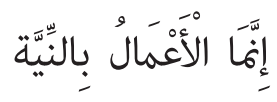

Hadits ini menjelaskan bahwa segala sesuatu baik dan buruknya bergantung pada niat. Setiap manusia yang berakal akan melakukan amalan (pekerjaan) yang didahului dengan niat. Sesuatu yang tidak didahului dengan niat hanya dilakukan oleh orang yang sedang tidak sadar atau gila (Zuhaili, 2010). Berdasarkan rujukan hadits inilah behavioural intention of use dapat dikatakan memediasi hubungan antara usefulness dan ease of use terhadap actual system use.

Beberapa penelitian yang menggunakan Teori TAM adalah Pertiwi Aisyah Dilarbo (2017) yang menjelaskan bahwa kegunaan dan faktor kemudahan penggunaan adalah faktor yang penting dan sangat berpengaruh terhadap sikap penggunaan gojek. Kemudahan dan kegunaan sangat berpengaruh positif terhadap penggunaan gojek (Dilarbo, 2017).

Selain Pertiwi Aisyah Dilarbo teori TAM juga digunakan dalam penelitian Tio Kharisma Yunanto (2016). Hasil penelitian Tio Kharisma Yunanto menyatakan bahwa perceived ease of use berpengaruh sangat signifikan terhadap penggunaan gojek dengan tingkat signifikansi sebesar 0,038. menurutnya hadirnya gojek di kota Tangerang Selatan (2016) memudahkan pengguna layanan jasa transportasi umum untuk mengakses dan melakukan aktivitas seharihari dengan lebih efektif (Yunanto, 2016).

Penelitian ini terinspirasi dari kedua penelitian tersebut yakni penelitian pertiwi Aisyah 
Dilarbo dan Tio Kharisma Yunanto. Namun yang membedakannya adalah terdapat variabel intervening berupa behavioural intention of use.

Gojek mengklaim memiliki 3 pilar yang kokoh yang pertama yaitu kecepatan yang dimaknai dengan sigap dan tanggap dalam melayani customer, yang kedua inovasi dalam peningkatan layanan sehingga mampu memberikan kemudahan bagi pengguna, yang ketiga adalah dampak sosial (The 3 Gojek Pilars, 2020).

Namun pada proses penggunaan sistem aplikasinya klaim gojek tersebut belum sepenuhnya sesuai dengan fakta yang ada, contohnya aplikasi gojek sering error.Peta pada aplikasi pun sering error. Pada layanan gofood, tentunya kita memerlukan lokasi agar memudahkan driver dalam mengantar makanan, pada bagian ini seringkali sistem tidak mampu membaca lokasi padahal pengguna telah mengaktifkan lokasi pada sistem android.

Berdasarkan permasalahan tersebut, penelitian ini bertujuan untuk menguji bagaimana pengaruh TAM terhadap penggunaan aplikasi gojek pada mahasiswa di kota Palembang dan menganalisis prinsip dasar Ekonomi Islam yang ada di dalam gojek.

\section{METODE}

Teknik pengumpulan sampel dalam penelitian ini menggunakan purposive sampling (Sugiyono, 2017). Sampel yang dipilih adalah mahasiswa Universitas Islam Negeri Raden Fatah Palembang dan Universitas Sriwijaya yang aktif dalam menggunakan gojek. Sumber data merupakan data primer berupa kuisioner. Penelitian ini digunakan untuk menguji hubungan antara usefulness dan ease of use terhadap behavioural intention of use melalui actual system use dengan menggunakan perangkat statistik structural equation model (SEM) Amos versi 21.. SEM juga dapat mengidentifikasi dimensi-dimensi sebuah konsep atau konstruk dan juga dapat mengukur pengaruh atau hubungan faktor yang akan diidentifikasi dimensi-dimensinya (Hendratman, 2010).

\section{HASIL DAN PEMBAHASAN}

Kuisioner yang disebarkan dalam penelitian ini sebanyak 200 kuisioner dan dikembalikan sebanyak 200 kuisioner. Jumlah ini menunjukkan response rate sebesar $100 \%$.

Tabel 1 menunjukan bahwa nilai reliabilitas berada $>0,70$. Artinya indikator yang digunakan reliabel dan mampu menjelaskan variabel laten yang dibentuknya. Sedangkan average variance extracted $>0,50$ artinya model ini telah memenuhi syarat dan ketentuan untuk melakukan uji tahap selanjutnya.

Selanjutnya untuk melakukan pengujian SEM, diperlukan pengukuran model dan pengujian model struktural yang disebut dengan confirmatory factor analysis. 
Tabel 1. Hasil Uji Reliabilitas

\begin{tabular}{|c|c|c|c|c|c|c|}
\hline Indikator & Loading & Error & 1-Loading & $\begin{array}{l}\text { Standar } \\
\text { Loading }^{2}\end{array}$ & CR & AVE \\
\hline$U$ & 0,664 & 0,478 & 0,336 & & & \\
\hline$U$ & 0,537 & 0,639 & 0,463 & & & \\
\hline$U$ & 0,655 & 0,487 & 0,345 & 8,586 & 0,834 & 0,776 \\
\hline$U$ & 0,793 & 0,316 & 0,207 & & & \\
\hline$U$ & 0,780 & 0,335 & 0,220 & & & \\
\hline$U$ & 0,864 & 0,218 & 0,136 & & & \\
\hline EOU & 0,821 & 0,276 & 0,179 & & & \\
\hline EOU & 0,680 & 0,459 & 0,320 & & & \\
\hline EOU & 0,893 & 0,173 & 0,107 & 7,578 & 0,862 & 0,809 \\
\hline EOU & 0,583 & 0,592 & 0,417 & & & \\
\hline EOU & 0,812 & 0,285 & 0,188 & & & \\
\hline $\mathrm{BIOU}$ & 0,845 & 0,246 & 0,155 & & & \\
\hline $\mathrm{BIOU}$ & 0,912 & 0,147 & 0,088 & 6,314 & 0,882 & 0,835 \\
\hline $\mathrm{BIOU}$ & 0,645 & 0,483 & 0,355 & & & \\
\hline $\mathrm{BIOU}$ & 0,755 & 0,372 & 0,245 & & & \\
\hline ASU & 0,770 & 0,354 & 0,230 & & & \\
\hline ASU & 0,784 & 0,337 & 0,216 & 4,438 & 0,850 & 0,789 \\
\hline ASU & 0,665 & 0,493 & 0,335 & & & \\
\hline
\end{tabular}

Tabel 2. Hasil Pengujian CFA

\begin{tabular}{|c|c|c|c|c|c|c|c|}
\hline & & & Estimate & S.E. & C.R. & $\mathbf{P}$ & Label \\
\hline BIOU & $<---$ & EOU & ,259 & ,132 & 1,964 & ,049 & par_3 \\
\hline $\mathrm{BIOU}$ & $<---$ & $U$ & ,427 & , 160 & 2,675 & ,007 & par_5 \\
\hline ASU & $<--$ & EOU & ,233 & ,112 & 2,087 & ,037 & par_1 \\
\hline ASU & $<---$ & $\mathrm{U}$ & 308 & ,142 & 2,172 & ,030 & par_2 \\
\hline ASU & $<--$ & $\mathrm{BIOU}$ &, 538 & ,090 & 5,984 & 000 & par_4 \\
\hline Y4 & $<---$ & BIOU & 1,000 & & & & \\
\hline Y5 & $<--$ & $\mathrm{BIOU}$ & 1,025 & ,103 & 9,917 & 000 & par_7 \\
\hline Y6 & $<---$ & BIOU & 1,045 & 101 & 10,305 & 000 & par_8 \\
\hline$\times 7$ & $<--$ & EOU & 1,000 & & & & \\
\hline$x 8$ & $<---$ & EOU & ,832 & ,080 & 10,389 & 000 & par_9 \\
\hline$\times 9$ & $<---$ & EOU & 1,093 & ,072 & 15,164 & 000 & par_10 \\
\hline X10 & $<---$ & EOU & ,732 & ,086 & 8,491 & 000 & par_11 \\
\hline X11 & $<---$ & EOU & ,986 & ,075 & 13,104 & 000 & par_12 \\
\hline $\mathrm{X} 1$ & $<---$ & $\mathrm{U}$ & 1,000 & & & & \\
\hline $\mathrm{X} 2$ & $<---$ & $\mathrm{U}$ & ,830 & ,119 & 7,007 & 000 & par_13 \\
\hline X3 & $<---$ & $\mathrm{U}$ & ,985 & ,118 & 8,318 & 000 & par_14 \\
\hline$\times 4$ & $<---$ & $\mathrm{U}$ & 1,192 & ,123 & 9,655 & 000 & par_15 \\
\hline$\times 5$ & $<---$ & $\mathrm{U}$ & 1,177 & ,126 & 9,351 & 000 & par_16 \\
\hline$x 6$ & $<---$ & $U$ & 1,308 & ,128 & 10,195 & 000 & par_17 \\
\hline Y1 & $<---$ & ASU & 1,000 & & & & \\
\hline Y2 & $<---$ & ASU & 1,087 & ,069 & 15,811 & 000 & par_18 \\
\hline Y3 & $<---$ & ASU & ,749 & ,077 & 9,742 & 000 & par_19 \\
\hline Y7 & $<---$ & BIOU & ,892 & 105 & 8,470 & 000 & par_20 \\
\hline
\end{tabular}


Berdasarkan tabel 2, dapat dilihat bahwa nilai critical ratio (CR) $\geq 1,96$ dan probability $<0,05$ sehingga model ini dikatakan valid. Hasil ini menunjukkan bahwa hipotesis diterima dan variabel-variabelnya positif dan signifikan secara statistik. Hubungan antar variabel secara langsung dan tidak langsung dapat dilihat dari hasil uji hipotesis.

Tabel 3. Pengaruh Langsung

\begin{tabular}{ccccccc}
\hline & & & CR & P & $\begin{array}{c}\text { Estimate Standardized } \\
\text { Regression }\end{array}$ & $\begin{array}{c}\text { Pengaruh } \\
\text { Langsung }\end{array}$ \\
\hline BIOU & $<---$ & EOU & 1,964 & 0,049 & 0,279 & $27,9 \%$ \\
BIOU & $<---$ & U & 2,657 & 0.007 & 0,374 & $37,4 \%$ \\
ASU & $<---$ & EOU & 2,067 & 0,037 & 0,224 & $22,4 \%$ \\
ASU & $<---$ & U & 2,172 & 0,030 & 0,241 & $24,1 \%$ \\
ASU & $<---$ & BIOU & 5,984 & 0,000 & 0,482 & $48,2 \%$ \\
\hline
\end{tabular}

Tabel 3 menjelaskan bahwa ease of use berpengaruh secara positif dan signifikan terhadap behavioural intention of use sesuai dengan penelitian sebelumnya(Anggraeni, 2016; Ricky, 2016), usefulness use berpengaruh secara positif dan signifikan terhadap behavioural intention of use sesuai dengan penelitian sebelumnya (Al Harbi, 2014; Fatmawati, 2015) ease of use berpengaruh secara positif dan signifikan terhadap actual system use sesuai dengan penelitian sebelumnya (Istiarni \& Hadiprajitno, 2014; Laihad, 2013), usefulness berpengaruh secara positif dan signifikan terhadap actual system use sesuai dengan penelitian sebelumnya (Sari, 2015; Wida et al., 2016) dan behavioural intention of use berpengaruh secara positif dan signifikan terhadap actual system use sesuai dengan penelitian sebelumnya (Hendra \& R, 2016; Makanyeza, 2017).

Tabel 4. Pengaruh Tidak Langsung

\begin{tabular}{clccc}
\hline No & Variabel Eksogen & Indirect Effect & t hitung & Persentase \\
\hline $\mathbf{1}$ & Usefulness & 0,135 & 3.695 & $1,8 \%$ \\
\hline $\mathbf{2}$ & Ease of Use & 0,180 & 2,142 & $3,24 \%$ \\
\hline
\end{tabular}

Berdasarkan tabel 4 dapat diketahui bahwa usefulness berpengaruh secara positif dan signifikan terhadap actual system use melalui behavioural intention of use sesuai dengan penelitian sebelumnya(Fatmawati, 2015; Hendra \& R, 2016; Sari, 2015) dan ease of use berpengaruh secara positif dan signifikan terhadap actual system use melalui behavioural intention of use sesuai dengan penelitian sebelumnya (Anggraeni, 2016; Hendra \& R, 2016; Laihad, 2013).

Dari tabel 3 dan 4 dapat diketahui bahwa ketujuh hipotesis diterima, sehingga meskipun terdapat kelemahan dari gojek berupa aplikasi yang sering error dan ter log out, peta sering tidak akurat dan terjadi pembelian akun, sehingga terdapat perbedaan nama pengemudi dan plat kendaraan, hal ini tidak berdampak besar dalam keputusan pengguna terutama mahasiswa di kota Palembang untuk tetap menggunakan aplikasi gojek, karena manfaat dan kemudahan yang dirasakan lebih besar. 
Dalam pandangan Ekonomi Islam, gojek termasuk dalam muamalah. Secara garis besar kaidah yang berlaku adalah:

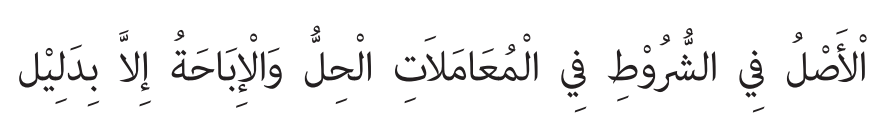

"Hukum asal dalam muamalat diperbolehkan, kecuali ada dalil yang mengharamkannya" (Fauzia, 2014)

Atas dasar kaidah ini, maka segala kegiatan ekonomi Islam yang membawa kemaslahatan dan tidak ada dalil yang melarangnya diperbolehkan. Oleh karena itu, penggunaan aplikasi ojek online khususnya gojek hukumnya adalah mubah, karena tidak ada dalil yang melarangnya.

Aplikasi Gojek dalam prinsip dasar Ekonomi Islam tidak terlepas dari nilai-nilai ketauhidan, kemaslahatan, keadilan, ta'awwun dan keseimbangan. ketauhidan yang dimaksud adalah segala aktifitas manusia dan hubungannya dengan sumber daya alam dan manusia (muamalah) dibingkai dengan kerangka hubungan dengan Allah dalam kaitan mempertanggungjawabkan aktifitas Ekonomi yang dilakukannya diantaranya ikhlas dalam melaksanakan tugas mengantarkan penumpang atau mengirimkan pesanan ke tempat yang dituju tepat waktu. Prinsip dalam menjalankan tugas tersebut adalah realisasi pengamalan makna kejujuran dan makna

Gojek juga memberikan kemaslahatan khususnya mahasiswa diantaranya adalah memberikan kemudahan dalam aktifitas sehari-hari. Dengan adanya gojek mahasiswa lebih terbantu untuk melaksanakan kegiatan seperti memesan gofood, mengantar ke tempat tujuan dan membeli barang (goshop).

Selain itu prinsip keadilan juga diberlakukan, salah satunya dapat dilihat dari penyediakan jasa sesuai dengan permintaan pengguna dengan transparansi harga sesuai dengan jarak tempuh yang digunakan. Hal ini juga termasuk dalam prinsip ta'awwun ketika pengguna memperoleh manfaat dan driver memperoleh upah dari manfaat yang diberikan.

Gojek juga bekerjasama dengan korporasi dan membantu usaha kecil menengah dalam mengembangkan bisnisnya. Contohnya dalam akad kerjasama gotix, gomart dan goshop. Gojek bekerjasama dengan cinemas dalam penjualan tiket, kemudian bekerjasama dengan indomaret dan alfamart dalam menyediakan jasa belanja yang kemudian diantarkan ke lokasi pengguna dengan tambahan ongkir sesuai jarak dan gojek juga turut membantu usaha-usaha kecil seperti toko-toko online. Pembeli dapat memesan barang dari toko online melalui aplikasi gojek, kemudian gojek akan memberikan talangan dana kepada penjual dan akan mengantarkan barang kepada pembeli dengan tambahan ongkir sesuai jarak. Dalam hal ini gojek turut membantu perkembangan ekonomi dalam berbagai sektor. Jika hal ini dilakukan secara konsisten maka akan terwujud prinsip keseimbangan sesuai dengan prinsip dasar ekonomi Islam.

\section{SIMPULAN}

Hasil penelitian ini menunjukkan bahwa behavioural intention of use atau niat adalah variabel yang sangat mempengaruhi keinginan seseorang dalam menggunakan teknologi khususnya aplikasi gojek pada mahasiswa di kota Palembang. Gojek telah diterima dengan 
baik pada kalangan mahasiswa di kota Palembang. Meskipun banyak kendala dalam penggunaan gojek, hal ini tidak berdampak besar dalam penggunaan aktual karena manfaat dan kemudahan penggunaan yang dirasakan jauh lebih besar sehingga menimbulkan niat untuk menggunakan yang berdampak terhadap penggunaan aktual sesuai dengan teori TAM dan TRA. Selain itu gojek juga memenuhi kelima prinsip dasar ekonomi Islam berupa ketauhidan, keadilan, kemaslahatan, ta'awwun dan keseimbangan.

Disarankan kepada Perusahaan PT. Gojek Indonesia untuk meningkatkan kualitas aplikasi dan pelayanan khususnya dalam bidang kemudahan penggunaan, agar kinerja gojek terus meningkat yang akan berimplikasi pada banyaknya pengguna. Selain itu, manfaat hanya memiliki pengaruh tidak langsung sebesar 1,6\% terhadap penggunaan aktual melalui minat mahasiswa. Berdasarkan fakta ini disarankan kepada PT. Gojek Indonesia untuk memberikan manfaat yang lebih besar terhadap para pengguna misalnya menambahkan fitur-fitur yang berguna dalam aktifitas sehari-hari sehingga meningkatkan minat pengguna yang menimbulkan penggunaan aktual secara terus menerus.

Untuk penelitian selanjutnya, jika dalam penelitian ini karakteristik hanya bagian dari penentuan sampel, maka disarankan untuk menambah variabel eksternal berupa karakteristik seperti tempat kuliah, usia dan tingkat pendidikan, sehingga mampu menjelaskan secara lebih terperinci bagaimana persepsi mahasiswa mengenai gojek sesuai dengan tempat kuliah, usia dan tingkat pendidikan.

\section{REFERENSI}

Agustini. (2014). (Pdf) Penerapan Sistem Terintegrasi Panduan Pariwisata Berbasis Mobile Untuk Pelaku Pariwisata Di Kabupaten Buleleng Dengan Model Tam. Jurnal Pendidikan Teknik Informatika. Https://Www.Researchgate.Net/Publication/313033778_Penerapan_ Sistem_Terintegrasi_Panduan_Pariwisata_Berbasis_Mobile_Untuk_Pelaku_Pariwisata_Di_ Kabupaten_Buleleng_Dengan_Model_Tam

Al Harbi, S. (2014). Using The Technology Acceptance Model In Understanding Academics' Behavioural Intention To Use Learning Management Systems Membahas Tentang E-Learning. Ijacsa, 05, 01.

Anggraeni, R. (2016). Pengaruh Persepsi Kemudahan Penggunaan Dan Persepsi Kegunaan Terhadap Niat Untuk Menggunakan Dan Penggunaan Aktual Layanan Jejaring Sosial Berbasis Lokasi (Studi Pada Mahasiswa Fakultas Ekonomi Dan Bisnis Universitas Brawijaya Malang). Ekonomi Bisnis, 20, 1.

App Ap, Diakses 2020. (N.D.). App Ape-Mobile App Market Intelligence, Analytics. Retrieved June 28, 2020, From Https://En.Appa.Pe

Dilarbo, P. A. (2017). Pengaruh Persepsi Kegunaan Dan Persepsi Kemudahan Penggunaan Terhadap Sikap Perilaku Penggunaan Aplikasi Go-Jek Di Kota Malang / Dilarbo / Jurnal Aplikasi Bisnis. Http://Jab.Polinema.Ac.Id/Index.Php/Jab/Article/View/85

Fatmawati, E. (2015). Technology Acceptance Model Untuk Menganalisis Penerimaan Terhadap Sistem Persepsi Kebermanfaatan. Jurnal Iqra, 09, 1.

Fauzia, I. Y. F. (2014). Prinsip Dasar Ekonomi Islam Perspektif Maqashid Al-Syariah. Kencana. 
Hendra, J., \& R, A. I. (2016). Aplikasi Model TAM Terhadap Pengguna Layanan Internet Banking Di Kantor Bank Jatim Cabang Situbondo. Ecobuss, 4(1), 40-48.

Hendratman, D. (2010). Analisis Pengaruh Kualitas Hubungan Bisnis Dengan Outlet Dan Strategi Pelayanan Outlet Terhadap Kinerja Penjualan Dalam Meningkatkan Loyalitas Outlet (Studi Kasus Pt. Indosat Semarang) [Masters, Diponegoro University]. Http:// Eprints.Undip.Ac.Id/63334/

Istiarni, P. R. D., \& Hadiprajitno, P. B. (2014). Analisis Pengaruh Persepsi Manfaat, Kemudahan Penggunaan Dan Kredibilitas Terhadap Minat Penggunaan Berulang Internet Banking Dengan Sikap Penggunaan Sebagai Variabel Intervening (Studi Empiris: Nasabah Layanan Internet Banking Di Indonesia). Diponegoro Journal of Accounting, 3(2), 888-897.

Kock, J. (2017). The Technology Acceptance Model (TAM). An OverviewJohannes Köck-Google Buku. Grin Publishing. Https://Books.Google.Co.Id/ Books?Id=Ftq7 dwaaqbaj\&Printsec=Frontcover\&Dq=Technology+Acceptance+ Model\&Hl=Id\&Sa=X\&Ved=2ahukewi068bupknqahvswx0kht9bdmqq6aewanoecamqag\# $\mathrm{V}=$ Onepage \&Q=Technology $\% 20$ acceptance $\% 20$ model $\& \mathrm{~F}=$ False

Laihad, R. C. Y. (2013). PENGARUH PERILAKU WAJIB PAJAK TERHADAP PENGGUNAAN E-FILING WAJIB PAJAK DI KOTA MANADO. Jurnal EMBA: Jurnal Riset Ekonomi, Manajemen, Bisnis Dan Akuntansi, 1(3), Article 3. Https://Doi.Org/10.35794/Emba.V1i3.1938

Makanyeza, C. (2017). Determinants Of Consumers' Intention To Adopt Mobile Banking Services In Zimbabwe. International Journal Of Bank Marketing, 35, 997-1017. Https:// Doi.Org/10.1108/IJBM-07-2016-0099

Permana, P. A. (2017). Gojek Super App: Ojek Online, Taksi Online, Pesan Makan, Kirim Barang, Pembayaran. Journal Speed. Https://Www.Gojek.Com/

Ricky, A. (2016). Pengaruh Perceived Usefulness Dan Perceived Ease Of Use Terhadap Behavioural Intention Dengan Pendekatan Technology Acceptance Model (TAM) Pada Pengguna Instant Messaging LINE Di Indonesia. Jurnal Siasat Bisnis, 20, 1.

Sari, M. P. (2015). Pengaruh Perceived Usefulness Dan Perceived Ease Of Use Terhadap Actual System Usage (Efisiensi Pengisian Spt) Menurut Persepsi Wajib Pajak (Survey Terhadap Pengusaha Kena Pajak Pada Kpp Pratama Bandung Cibeunying). Eproceeding Of Management, 02, 03.

Sugiyono. (2017). Metode Penelitian Kuantitatif, Kualitatif Dan $R \& D$. Alfabeta.

Tentang Kami / Gojek. (N.D.). Retrieved June 28, 2020, From Https://Www.Gojek.Com/About/

The 3 Gojek Pilars. (2020).

Wida, P. A. M. W., Yasa, N. N. K., \& Sukaatmadja, I. P. G. (2016). Aplikasi Model Tam (Technology Acceptance Model) Pada Perilaku Pengguna Instagram. Jurnal Ilmu Manajemen Mahasaraswati, 6(2), 101948.

Yunanto, T. K. (2016). Pengaruh Perceived Ease Of Use, Word Of Mouth, Dan Brand Image Terhadap Keputusan Penggunaan Layanan Jasa Transportasi Gojek Di Kota Tangerang Selatan. Http://Repository.Uinjkt.Ac.Id/Dspace/Handle/123456789/39743

Zuhaili, W. (2010). Fiqih Islam Wa Adillatuhu. Gema Insani. 